\title{
Gerador de alta frequência como recurso para tratamento de úlceras por pressão: estudo piloto
}

\author{
High frequency generator as treatment in \\ scar pressure ulcers: pilot study
}

\section{Raciele Ivandra Guarda Korelo ${ }^{[\mathrm{a}]}$, Joselia Jucirema Jarschel de Oliveira ${ }^{[\mathrm{b}]}$, Renata Simone Araújo Souza ${ }^{[c]}$, Reni de Fátima Hullek ${ }^{[c]}$, Luiz Claudio Fernandes ${ }^{[\mathrm{d}]}$}

[a] Fisioterapeuta, doutoranda em Educação Física pela Universidade Federal do Paraná (UFPR) e docente do curso de Fisioterapia da UFPR, Curitiba, PR, Brasil, e-mail: raciele@ufpr.br

[b] Fisioterapeuta, especialista em Fisioterapia Cardiorrespiratória pela Universidade Tuiuti do Paraná (UTP), fisioterapeuta do Hospital de Clínicas do Paraná e docente do curso de Fisioterapia da Faculdade Dom Bosco, Curitiba, PR, Brasil, e-mail: josepar@ig.com.br

[c] Fisioterapeutas graduadas pela Faculdade Dom Bosco, Curitiba, PR, Brasil, e-mails: renatafisioestetica@hotmail.com; hulekre@hotmail.com

[d] Biólogo, doutor em Ciências pela Universidade de São Paulo (USP), pós-doutor em Sinalização Intracelular pela New Mexico University (EUA) e professor titular da Universidade Federal do Paraná (UFPR), Curitiba, PR, Brasil, e-mail: lcfer@ufpr.br

\section{Resumo}

Introdução: Após a descoberta da existência de campos elétricos em lesões de tecidos, começou-se a empregar a aplicação externa de correntes elétricas na cicatrização de feridas. Baseados nesses conceitos, estudos mostram que a estimulação elétrica por alta frequência (HF - high frequency) é concebida como uma opção útil no processo cicatricial. Apesar dessa afirmativa, não há consenso entre os pesquisadores para sua utilização no tratamento de afecções da pele, sendo utilizada empiricamente no tratamento de feridas crônicas. Objetivo: Investigar o uso do gerador de alta frequência sobre a dor, cicatrização e área de superfície de úlceras de pressão (UP). Materiais e métodos: Estudo piloto de ensaio clínico controlado realizado na Unidade de Tratamento Intensivo do Hospital de Clínicas do Paraná em oito indivíduos (49,6 \$ 15,9 anos de idade), com diagnóstico clínico de UP grau II e III, classificados pela National Pressure Ulcer Advisory Panel (NPUAP). Indivíduos foram divididos em dois grupos: controle $(n=2)$ e alta frequência $(n=6)$, com aplicação diária durante dez dias. Avaliou-se dor (por 
meio da Escala Visual Analógica - EVA), processo de cicatrização da úlcera (por meio do Pressure Ulcer Scale for Healing - PUSH Tool e do Pressure Score Status Tool - PSST) e a área de superfície da úlcera (planimetria e ImageJ). Resultados: Houve efeito significativo intragrupo (pré e pós-intervenção) na utilização do gerador de alta frequência no processo de cicatrização (PUSH Tool de 8,6 $\pm 5,8$ para 5,1 $\pm 5,5, p=0,04$ e PSST de 31,3 $\pm 5,6$ para $18 \pm 6,5, p=0,02$ ) e área de superfície da úlcera (planimetria de 690,3 $\pm 622,6$ para $470 \pm 642,4, p=0,02$ e ImageJ de 786,5 $\pm 690,9$ para 537,0 $\pm 719,3, p=0,02$ ). Também houve diferença significativa entre os grupos controle e grupo alta frequência em todas as variáveis do estudo $(p=0,04)$. Conclusões: A utilização do gerador de alta frequência causou melhora na cicatrização de pacientes com UP. Contudo, são necessários mais estudos com maior número de indivíduos para corroborar tais resultados. Nesse contexto, esta pesquisa agrega valor à procura de alternativas de tratamento para UP.

Palavras-chave: Úlcera por pressão. Cicatrização de feridas. Estimulação elétrica.

\section{Abstract}

Introduction: Following the discovery of the presence of electric fields in tissue injury, started to employ the external application of electric currents in wound healing. Based on these concepts, studies show that high-frequency (HF) electrical stimulation is designed as a useful option in the healing process. Despite this statement, there is no consensus among researchers for its use in the treatment of skin disorders and is used empirically in the treatment of chronic wounds. Objective: To explore the application of high frequency generator in the treatment of pain, scarring and surface areas of pressure ulcers (PU). Materials and methods: Controlled clinical trial pilot study carried out in the Intensive Care Unit of Hospital de Clínicas of Paraná. Sample of 8 subjects (age of 49.6 \pm 15.9 ) diagnosed with II and III level degree of UP, following the National Pressure Ulcer Advisory Panel (NPUAP) classification. Subjects were split between groups: control $(n=2)$ and high frequency daily treatment $(n=10)$ in a period of 10 days. We assessed pain (by visual analog scale - VAS), the ulcer healing process (Pressure Ulcer Scale for Healing - PUSH Toll and the Pressure Score Status Tool - PSST) and ulcer surface area (planimetry and ImageJ). Results: A significant effect within group (before and after intervention) of high frequency generator treatment on the process of healing (PUSH Tool before: $8.6 \pm 5.8$; after: $5.1 \pm 5.5$; $p=0.04$ and PSST before: $31.3 \pm 5.6$; after: $18 \pm 6.5$; $p=0.02$ ), and on ulcer surface area (planimetry before: 690.3 \pm 622.6 ; after: $470 \pm 642.4 ; p=0.02$ and ImageJ before: $786.5 \pm$ 690; after: $537.0 \pm 719.3 ; p=0.02$ ). Also, we found a significant difference between group (control and high frequen$c y), p=0.04$. Conclusions: The treatment of high frequency generator caused improvement in healing UP patients. Although, we need more studies with larger number of subjects in order to confirm the findings. Regarding the UP treatment domain, this study adds in the searching for alternative interventions.

Keywords: Pressure ulcer. Wound healing. Electrical stimulation.

\section{Introdução}

Úlceras por pressão (UP) são áreas de necrose tissular ocasionadas por compressão, em um determinado período de tempo, do tecido entre uma proeminência óssea e uma superfície externa (1). Apesar da modernização dos cuidados de saúde, a prevalência de UP ainda é alta (2). Pacientes hospitalizados e com mobilidade comprometida apresentam frequência elevada de UP, sendo que os pacientes internados em Unidade de Terapia Intensiva (UTI) são extremamente vulneráveis a essa condição, pois estão expostos a inúmeros fatores de risco, como: instabilidade hemodinâmica, estado geral comprometido, condição nutricional desfavorável, além da limitação da mobilidade imposta pelo confinamento no leito e pelo número excessivo de dispositivos e tecnologias que dificultam a utilização de manobras de prevenção para UP (3). Dessa forma, as UP impactam negativamente os pacientes tanto social quanto economicamente, além de gerarem dor, perda de função e diminuição de suas qualidades de vida (4-6). A presença de UP leva à hospitalização prolongada, em média, por dois meses (7), e está associada à mortalidade prematura (8). 0 diagnóstico da UP 
é visual e classificado em níveis de I a IV, de acordo com os danos observados nos tecidos acometidos (3). Paralelamente, outros instrumentos de medicação foram criados para incluir parâmetros de avaliação da cicatrização como dimensão da úlcera (comprimento $\mathrm{x}$ altura $=\mathrm{cm}^{2}$ ), quantidade de exsudato e de tecido necrótico (2).

0 diagnóstico e o tratamento precoce permitem redução nos custos, prevenção da progressão e aceleração do processo de cicatrização. 0 tratamento local inclui desbridamento, limpeza, revestimento (penso), abordagens da colonização e infecção, agentes físicos (laser, ultrassom e eletroestimulação) e até tratamento cirúrgico (2).

Os agentes físicos começaram a ser empregados na cicatrização de feridas após a descoberta da existência de geração endógena de campos elétricos em lesão de tecidos, resultantes dos canais de sódio na membrana que permitem a difusão interna de sódio (9). De fato, estudos demonstraram que a estimulação elétrica de alta frequência (HF - high frequency) é uma boa opção no processo cicatricial, além de proporcionar alívio do quadro álgico (10-13).

0 gerador de alta frequência é um aparelho que opera com correntes alternadas (tensão elevada e baixa intensidade) e eletrodos de vidro que contêm em seu interior vácuo (ar rarefeito) ou gás (Neon, Xenon ou Argon) (10-12). Aliado à geração de campo elétrico, advoga-se que o gerador de HF tem capacidade de produzir efeitos fisiológicos decorrentes de: 1) efeitos térmicos produzidos pela corrente ao atravessar o organismo, gerando a produção de calor local. 0 efeito térmico causa vasodilatação periférica local, aumentando o fluxo sanguíneo e o aporte de oxigênio, incrementando, portanto, o trofismo, a oxigenação e o metabolismo celular; 2) efeito do ozônio devido ao faiscamento produzido pela corrente ao atravessar o eletrodo. 0 uso criterioso do ozônio $\left(\mathrm{O}_{3}\right)$ é providencial, porque elimina os agentes patogênicos e, em seguida, libera oxigênio $\left(\mathrm{O}_{2}\right)$, ativa a fibroplasia para a elaboração de matriz intercelular, proliferação de queratinócitos e, consequentemente, a cura(14-18).

Desse modo, por essas "qualidades", considera-se o gerador de alta frequência como alternativa para $o$ tratamento de feridas com dificuldades de reparação $(10,13)$. Apesar dessa afirmativa, não há consenso entre os pesquisadores para sua utilização no tratamento de afecções da pele, sendo utilizado empiricamente no tratamento de feridas crônicas. Assim, para ajudar na elucidação desse problema, este estudo objetiva investigar o efeito da estimulação elétrica com gerador de alta frequência sobre a dor, cicatrização e a área de superfície de úlceras de pressão.

\section{Materiais e métodos}

Trata-se de um estudo piloto de ensaio clínico controlado, realizado na Unidade de Tratamento Intensivo do Hospital de Clínicas do Paraná e aprovado pelo Comitê de Ética em Pesquisa da Instituição (n. 2410.017/2011/02) e do Hospital de Clínicas do Paraná (n. 0011.020.000-11).

Indivíduos de ambos os sexos foram selecionados, com idade superior a 25 anos, diagnóstico clínico de úlcera de pressão (UP), sedentários e sob tratamento clínico baseado apenas em curativos simples (medidas gerais de higienização da úlcera com soro fisiológico e oclusão com gaze). 0 grau da úlcera foi definido por um mesmo avaliador/pesquisador, respeitando-se a classificação adotada e preconizada pela National Pressure Ulcer Advisory Panel (NPUAP) (1), sendo selecionados apenas indivíduos com UP de grau II e III.

Indivíduos inconscientes foram excluídos, assim como os que apresentavam febre, marca-passo, hipertensão arterial sistêmica não controlada, osteomielite, dores de origem desconhecida, gestantes, úlceras com necrose, indivíduos com monitorização por equipamentos, em que o gerador de alta frequência pudesse interferir, e que estivessem fazendo uso de medicamentos orais ou tópicos atuando diretamente no processo de cicatrização.

Todos os pacientes foram submetidos a uma avaliação para coleta de dados demográficos e clínicos, realizada pelo mesmo avaliador. A avaliação ocorreu em dois momentos (antes da intervenção e após dez dias), por meio da Escala Visual Analógica (EVA) para quantificação da dor, pelo PUSH Tool (19) e pelo PSST (20) para verificação da cicatrização da úlcera e, ainda, mensurou-se a área da úlcera por meio da planimetria clássica (21) e digitalização das imagens (22).

Para a realização da planimetria, utilizou-se embalagem estéril para uso de materiais hospitalares de folha dupla e transparente (tipo acetato). As folhas transparentes foram sobrepostas em contato com a úlcera e fixadas para o contorno da borda da úlcera com caneta, de forma que o lado estéril ficasse em contato com a lesão, sendo descartado após a medição. Ficou em posse do avaliador o acetato que não teve contato com a úlcera (23) (Figura 1). 
Após o registro no papel vegetal foi determinada a área total da úlcera: 1) sobreposição do papel vegetal em papel milimetrado (21), efetuando-se a contagem da quantidade de quadrados dentro da área da úlcera para determinar o valor de sua área em milímetros quadrados $\left(\mathrm{mm}^{2}\right) ; 2$ ) digitalização das imagens obtidas no papel vegetal para mensuração através do programa Image $J^{\circledR}(22)$, comparadas com um referencial padrão com área conhecida (Figura 2).

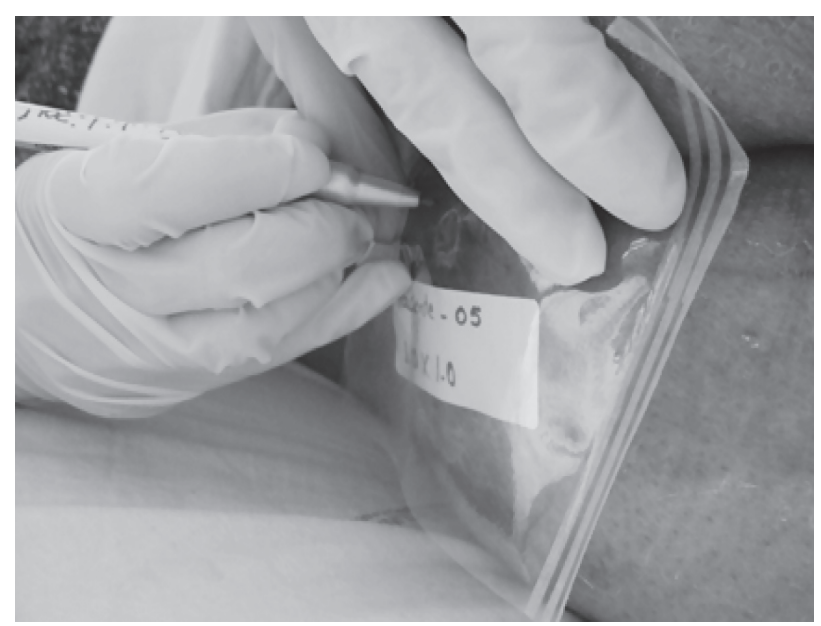

Figura 1 - Delimitação do contorno da área da úlcera no acetato Fonte: Dados da pesquisa.

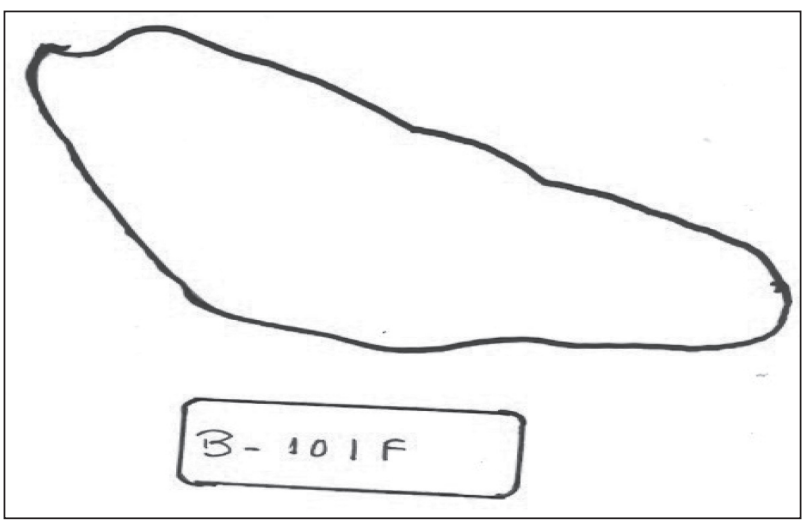

Figura 2 - Método planimétrico: digitalização da área da úlcera no acetato

Fonte: Dados da pesquisa.

Todos os materiais utilizados na avaliação foram submetidos à desinfecção, antes e após cada mensuração, com solução Peresal (Peróxido de Hidrogênio) de uso hospitalar. Após avaliação, os sujeitos foram divididos aleatoriamente em: grupo alta frequência (HF) e grupo controle. A randomização foi feita por meio de sorteio. Neste estudo, apenas o avaliador estava cego quanto à intervenção realizada.

Para aplicação da alta frequência foi utilizado o equipamento Plus ${ }^{\circledR}$, da marca Tone Derm, que opera com corrente alternada. Utilizou-se a técnica de faiscamento (Figura 3), com amplitude a 80\% e eletrodo do tipo bico, contornando toda a úlcera e o seu interior, afastado do tecido o suficiente para evitar o contato e a contaminação. Os sujeitos receberam dez aplicações diárias durante, no máximo, dez minutos, sendo variável com o tamanho da lesão ( 1 minuto para cada $\mathrm{cm}^{2}$ ), totalizando duas semanas de intervenção.

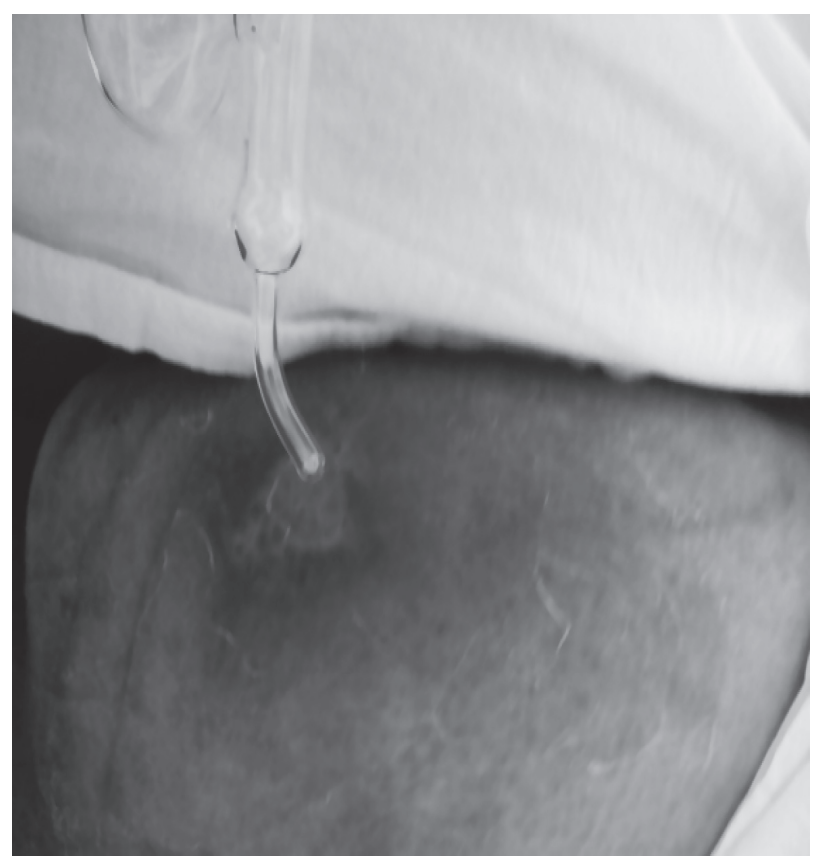

Figura 3 - Aplicação da microcorrente na úlcera Fonte: Dados da pesquisa.

O grupo controle não foi submetido a qualquer intervenção fisioterapêutica, mas foi mantida sua rotina de curativos simples (medidas gerais de higienização da úlcera com soro fisiológico e oclusão com gaze).

Os pacientes foram avaliados no início do tratamento (T0) e após completarem duas semanas por um mesmo avaliador (T10).

\section{Análise estatística}

Foi utilizado o software Statistical Package for the Social Sciences (SPSS), versão 16.0 para Windows. 
Os dados foram submetidos ao teste Shapiro-Wilk para verificar a normalidade e estão apresentados como média e desvio padrão. As diferenças pré e pós-intervenção intragrupo foram determinadas usando-se o teste de Wilcoxon para dados não paramétricos, e as diferenças intergrupos foram determinadas usando-se o teste de Mann-Whitney para dados não paramétricos. Em toda a análise estatística foi adotado um nível de significância de $5 \%$, ou seja, p-valor $<0,05$.

\section{Resultados}

Foram avaliados 22 pacientes, dos quais 14 foram randomizados para os grupos, três receberam alta da UTI antes do período previsto para término da aplicação da HF, um teve óbito por complicações do seu quadro clínico e alguns dados não puderam ser coletados no segundo momento em dois pacientes devido à alteração do quadro de consciência (Figura 4). Assim, a amostra foi composta por oito pacientes com média de idade de 49,6 $\pm 15,9$ anos. As características demográficas, socioeconômicas e clínicas (Tabela 1) não demonstraram diferença significativa entre os grupos, exceto para as variáveis sexo e Índice de Massa Corporal (IMC).
Dor

Após dez aplicações (duassemanas detratamento) os pacientes não apresentaram melhora significativa da dor avaliada nos momentos pré e pós-tratamento (Tabela 2). Entretanto, houve diferença significativa na comparação entre os dois grupos, demonstrando melhoras somente para o grupo intervenção (Tabela 3).

\section{Processo de cicatrização}

Os pacientes do grupo HF apresentaram melhora significativa para o processo de cicatrização mensurado por meio do PUSH Tool, de 8,6 \pm 5,8 para 5,1 \pm $5,5, \mathrm{p}<0,04$, assim como por meio do PSST, de 31,3 \pm 5,6 para $18 \pm 6,5, p<0,02$ (Tabela 2). A análise entre os grupos demonstrou diferença significante para ambos os métodos de avaliação, $\mathrm{p}=$ 0,04 (Tabela 3).

\section{Área da úlcera}

Em relação à área da úlcera avaliada nos momentos pré e pós-tratamento, somente o grupo HF demonstrou redução significante mensurada por meio

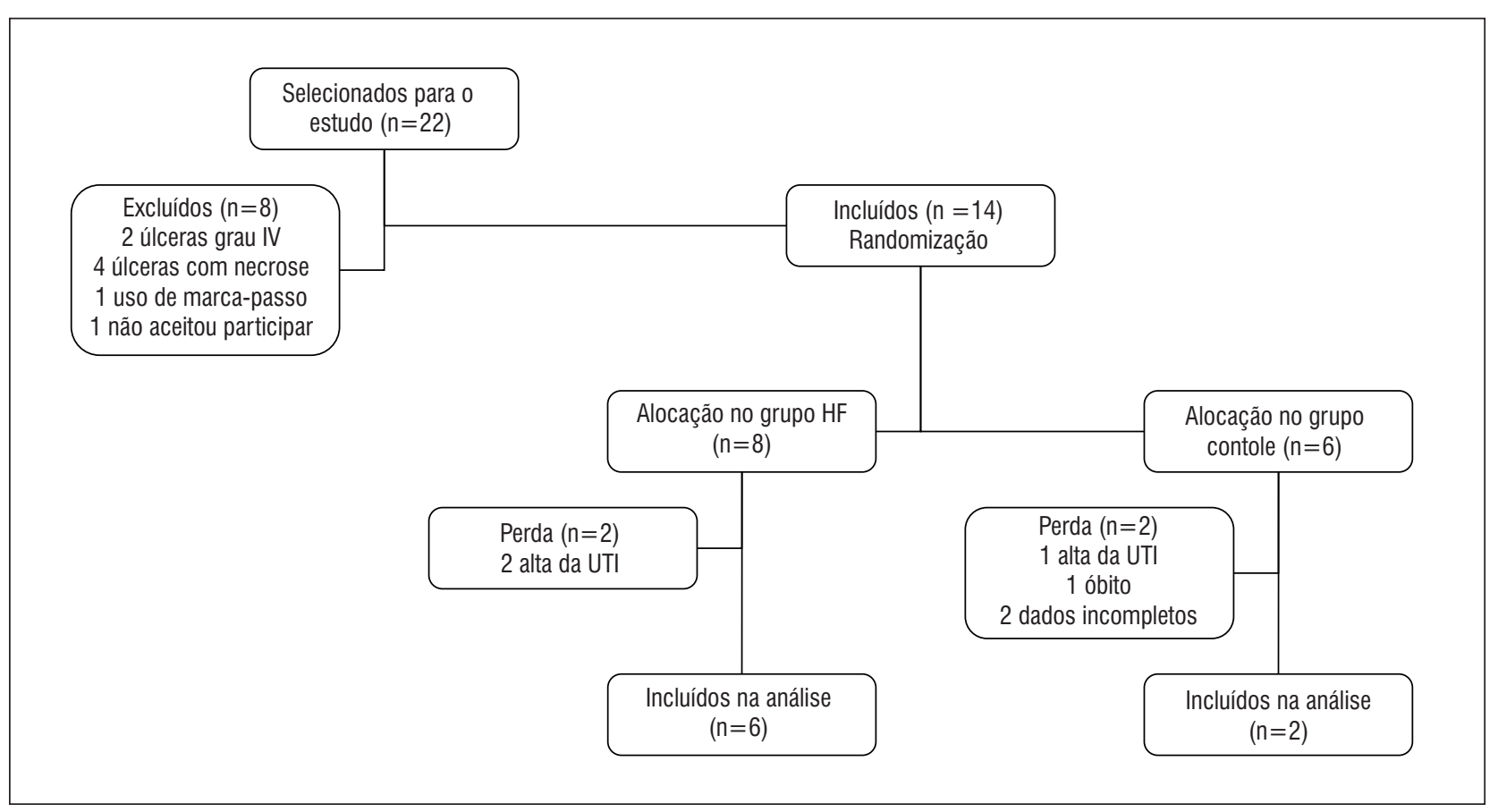

Figura 4 - Seleção, randomização e análise dos voluntários para o estudo Fonte: Dados da pesquisa. 
do papel vegetal, de 690,3 $\pm 622,6$ para $470 \pm 642,4$, $\mathrm{p}<0,02$, assim como por meio do programa Image J, de $786,5 \pm 690,9$ para $537,0 \pm 719,3, \mathrm{p}<0,02$ (Tabela 2). A análise entre os grupos demonstrou diferença significativa para ambos os métodos de avaliação, $\mathrm{p}=0,04$ (Tabela 3).

\section{Discussão}

Úlceras de pressão são determinantes no aumento do tempo de internamento, impactam em ônus para o sistema de saúde e a taxa de cronicidade da lesão revela a falta de resolutividade no processo (4-6). Portanto, o tratamento de feridas crônicas não é apenas desafio clínico, mas devido ao uso extensivo de recursos se tornou tema amplamente discutido em fóruns econômicos da área de saúde (7). Dessa forma, é necessária uma sistematização de ações para a prevenção e completa cura dos pacientes, sendo a utilização de recursos físicos o objeto de investigação por pesquisadores.

Entre as opções de tratamento por agentes físicos, o objeto desta pesquisa se refere à utilização da estimulação elétrica no aumento da cura por meio da

Tabela 1 - Características demográficas e clínicas dos sujeitos

\begin{tabular}{|c|c|c|c|}
\hline & $\begin{array}{c}\text { Grupo controle } \\
\qquad n=2\end{array}$ & $\begin{array}{c}\text { Grupo HF } \\
n=6\end{array}$ & p-valor \\
\hline Idade (anos, média \pm DP) & $65,5 \pm 4,9$ & $44,3 \pm 14,7$ & 0,099 \\
\hline \multicolumn{4}{|l|}{$\operatorname{Sexo}(n, \%)$} \\
\hline Feminino & $2(100)$ & $2(33,3)$ & $0,001^{*}$ \\
\hline Masculino & $0(0)$ & $4(66,6)$ & \\
\hline IMC $\left(\mathrm{m} / \mathrm{Kg}^{2}\right.$, média $\left.\pm \mathrm{DP}\right)$ & $28,9 \pm 3,2$ & $28,2 \pm 6,3$ & $0,012^{*}$ \\
\hline Dor (mediana, intervalo interquartil) & $5,5(5-6)$ & $6,5(0-10)$ & 0,122 \\
\hline PUSH Tool (média \pm desvio padrão) & $12,0 \pm 1,4$ & $8,6 \pm 5,8$ & 0,412 \\
\hline PSST (média \pm desvio padrão) & $25,5 \pm 0,7$ & $31,3 \pm 5,6$ & 0,093 \\
\hline \multicolumn{4}{|c|}{ Área da úlcera (mm², média \pm desvio padrão) } \\
\hline Papel vegetal & $757,0 \pm 196,5$ & $690,3 \pm 622,6$ & 0,214 \\
\hline ImageJ $\circledast$ & $966,5 \pm 249,6$ & $786,5 \pm 690,9$ & 0,333 \\
\hline
\end{tabular}

Legenda: IMC = Índice de Massa Corporal; PUSH = Pressure Ulcer Scale for Healing; PSST= Pressure Score Status Tool.

Fonte: Dados da pesquisa.

Tabela 2 - Valores das variáveis do estudo antes e após aplicação

\begin{tabular}{|c|c|c|c|c|c|c|}
\hline & \multicolumn{2}{|c|}{$\begin{array}{l}\text { Grupo controle } \\
\quad(n=2)\end{array}$} & \multirow[t]{2}{*}{$\mathrm{p}$-valor } & \multicolumn{2}{|c|}{$\begin{array}{c}\text { Grupo HF } \\
(n=6)\end{array}$} & \multirow[t]{2}{*}{$\mathrm{p}$-valor } \\
\hline & Pré & Pós & & Pré & Pós & \\
\hline Dor (mediana, intervalo) & $5,5(5-6)$ & $8,5(8-9)$ & 0,18 & $6,5(0-10)$ & $2(0-6)$ & 0,06 \\
\hline \multicolumn{7}{|l|}{ Cicatrização da úlcera } \\
\hline PUSH Tool (média \pm DP) & $12,0 \pm 1,4$ & $15,0 \pm 2,8$ & 0,18 & $8,6 \pm 5,8$ & $5,1 \pm 5,5$ & $0,04^{*}$ \\
\hline PSST (média \pm DP) & $25,5 \pm 0,7$ & $44,5 \pm 10,6$ & 0,18 & $31,3 \pm 5,6$ & $18 \pm 6,5$ & $0,02^{*}$ \\
\hline \multicolumn{7}{|l|}{ Área da lesão (mm²) } \\
\hline Papel vegetal (média $\pm \mathrm{DP})$ & $757,0 \pm 196,5$ & $2148,0 \pm 1770,6$ & 0,18 & $690,3 \pm 622,6$ & $470 \pm 642,4$ & $0,02^{*}$ \\
\hline ImageJ® (média $\pm \mathrm{DP})$ & $966,5 \pm 249,6$ & $2473,0 \pm 1861,1$ & 0,18 & $786,5 \pm 690,9$ & $537,0 \pm 719,3$ & $0,02^{*}$ \\
\hline
\end{tabular}

Legenda: PUSH= Pressure Ulcer Scale for Healing; PSST = Pressure Score Status Tool.

Fonte: Dados da pesquisa.

Nota: * $p$-valor $<0,05$ indicando diferença significativa 
Tabela 3 - Comparação das diferenças das médias entre o grupo controle e o grupo HF

\begin{tabular}{lccc}
\hline & \multicolumn{2}{c}{ Média do grau de melhora } & p-valor \\
& Controle $(\mathbf{n}=\mathbf{2})$ & HF $(\mathbf{n}=\mathbf{6})$ & \\
\hline Dor (mediana, intervalo) & $3,0 \pm 1,4$ & $-19,0 \pm 2,7$ & $0,04^{*}$ \\
Cicatrização da úlcera & & & $0,04^{*}$ \\
PUSH Tool (média \pm DP) & $3,0 \pm 1,4$ & $-21,0 \pm 2,5$ & $0,04^{*}$ \\
PSST (média \pm DP) & $19,0 \pm 9,8$ & $-80,0 \pm 2,8$ & \\
Área da lesão (mm², média \pm DP) & & & $0,04^{*}$ \\
Papel vegetal & $1391,0 \pm 1574,0$ & $-1322,0 \pm 157,6$ & $0,04^{*}$ \\
ImageJ ${ }^{8}$ & $1506,5 \pm 1611,4$ & $-1497,0 \pm 156,1$ & \\
\hline
\end{tabular}

Legenda: PUSH = Pressure Ulcer Scale for Healing; PSST = Pressure Score Status Tool.

Fonte: Dados da pesquisa.

Nota: * $p$-valor $<0,05$ indicando diferença significativa.

promoção da síntese proteica, inibição do crescimento bacteriano, facilitação da migração do tecido epitelial, melhora do fluxo sanguíneo e da resistência à tração de tecidos moles (24). Entretanto, o arsenal de recursos eletroterapêuticos é extenso e as pesquisas ainda não estabeleceram os parâmetros ideais para sua utilização. Dentre as correntes elétricas terapêuticas, o gerador de alta frequência merece destaque por apresentar resultados na cicatrização de feridas, além de proporcionar efeito anti-inflamatório e bactericida (10-13).

0 primeiro gerador de alta frequência foi desenvolvido por Werner Von Siemens na Alemanha, em 1857, que, por intermédio deste aparelho, conduziu os seus primeiros estudos sobre a ação do ozônio em bactérias e germes, e depois em mucosas de animais e humanos (12). A partir de então, o gerador de alta frequência vem sendo utilizado como tratamento em lesões da pele por profissionais fisioterapeutas (13). Esses aparelhos podem ser portáteis ou conjugados em aparelhos com outros recursos. São utilizados na estética em procedimentos faciais como: desinfecção do couro cabeludo em casos de seborreia, pós-depilação, foliculites, solução de continuidade da pele como úlceras e feridas; e também tem se mostrado eficaz no tratamento de psoríase, feridas infectadas e pós-extrações de cutículas.

0 gerador de alta frequência é um aparelho que trabalha com correntes alternadas (tensão elevada e baixa intensidade) que variam de acordo com cada fabricante, geradas a partir de dispositivo eletrônico que transforma a corrente elétrica de uso doméstico em correntes de alta frequência, transmitidas por eletrodos de vidros (10). Seus eletrodos são conectados geralmente por pressão, através da base metálica encaixada no porta-eletrodo. Os eletrodos de vidro podem conter em seu interior vácuo (ar rarefeito) ou gás (Neon, Xenon ou Argon). Com a passagem da corrente eletromagnética pelo ar ou pelo gás ocorre a ionização das moléculas, as quais, sobre o forte impacto energético, tornam-se fluorescentes e provocam a formação de ozônio, que possui ação bactericida (10-12). 0 ozônio $\left(\mathrm{O}_{3}\right)$ é uma substância instável, que, ao entrar em contato com a pele, se decompõe rapidamente em oxigênio molecular $\left(\mathrm{O}_{2}\right)$ e em oxigênio atômico $(0)$, sendo este altamente agressivo e com alto potencial oxidativo, proporcionando ação antimicrobiana por causar peroxidação de enzimas até a lise da membrana celular (12).

A ozionioterapia foi empregada durante muito tempo de forma empírica, criando um ceticismo sobre seus efeitos $(15,18)$. Aliado a isso, a falta de precisão dos geradores de ozônio, o charlatanismo das empresas, a falta de interesse político na sua regulamentação, a escassez de estudos controlados e a dificuldade em estabelecer a dose-resposta ideal têm mantido a ozionoterapia questionável na aplicação terapêutica e impedindo que seja mais utilizada $(14,15,17)$.

Atualmente, a ozonioterapia tem sido explorada como alternativa terapêutica no tratamento de muitas doenças agudas e crônicas, por ser capaz de intervir no equilíbrio de oxidorredução. 0 ozônio é um potente oxidante e, em contato com fluidos orgânicos, acarreta na formação de moléculas reativas de oxigênio, que influenciam eventos bioquímicos do metabolismo celular, o que pode proporcionar benefícios à reparação tecidual, além do efeito antimicrobiano $(13,15)$. 
Segundo Bocci (18), são muitas as possibilidades de indicação para o uso do ozônio de forma terapêutica, sendo que essas já possuem bons indícios comprovados para o tratamento de algumas situações clínicas. Além disso, várias vantagens dessa terapia são referidas na literatura, por exemplo, potente ação antimicrobiana, fácil aplicação sistêmica ou local, baixo custo e ausência de efeito adverso, intolerância ou contraindicação (18).

Para aplicação do recurso foi escolhida a técnica de faiscamento ou aplicação a distância, que consiste na aplicação do eletrodo a milímetros da pele, o que produz grande diferença de potencial entre o eletrodo e a pele, tornando o ar um condutor de eletricidade (10-11). A escolha deveu-se ao fato de o contato possibilitar risco de infecção do local.

Quanto à intensidade, Borges (10) afirma que se deve buscar o máximo de faiscamento ou luminosidade do eletrodo, associado ao conforto ou tolerância do paciente. Para aumentar a ação do eletrodo, pode-se passá-lo de forma que fique ligeiramente afastado da pele, ou ainda, sobre uma gaze seca.

No presente estudo, avaliou-se a dor (EVA), a cicatrização de feridas pelo PUSH Tool e PSST, além da área da superfície da úlcera (planimetria) de indivíduos com úlcera de pressão. Os resultados com a EVA demonstraram que o gerador de alta frequência apresenta tendência à redução do quadro álgico dos indivíduos, com apenas duas semanas de intervenção. Entretanto, ainda não é possível afirmar a capacidade da alta frequência em amenizar o quadro doloroso, o que ainda não foi discutido em estudos anteriores.

Para os instrumentos PUSH Tool e PSST foi possível verificar significância com tendência a resultados melhores para o grupo alta frequência. Já em relação à área da úlcera, apesar do pouco tempo de aplicação do recurso e pelo número reduzido da amostra, foi possível verificar que somente o grupo HF obteve diminuição expressiva da área, com significância ao comparar com o controle. Esses resultados sugerem a ação antimicrobiana da corrente que proporciona um ambiente mais adequado para a cicatrização (10-12).

Para Borges (10), a melhora do trofismo dérmico está relacionada a sua ação bactericida, pois a regeneração tecidual está prejudicada pela ação de bactérias, 0 que se justifica pelo aumento do fluxo sanguíneo, o qual aumenta a presença dos elementos de defesa do sangue na área lesada. 0 autor ressalta, ainda, que o gerador de alta frequência não deve ser utilizado em inflamações de estruturas profundas como tendões, ossos, articulações e músculos, pois não tem ação em profundidade.
O calor gerado pelas correntes de alta frequência, ao atravessar o organismo, provoca vasodilatação periférica local. Com isso, ocorre aumento do fluxo sanguíneo, melhorando o trofismo e a oxigenação do metabolismo celular. Entretanto, no gerador, o efeito térmico torna-se pouco pronunciado em relação a outros aparelhos de alta frequência, como o ondas curtas e o microondas, podendo-se perceber leve sensação de calor quando usadas potências mais elevadas, o que é pouco comum na prática clínica (10).

Os resultados deste estudo corroboram outro que avaliou a ação do gerador de alta frequência em verrugas ungueais vulgares, o qual apresentou resultados satisfatórios após 15 aplicações com periodicidade de três vezes ao dia, levando à cura completa da lesão. Pode-se perceber que nos diversos estudos o tempo de aplicação e frequência variam de um autor para outro (12).

0 estudo in vitro, com o objetivo de verificar a ação fungicida da HF em cultura de candida tropicalis, realizado com técnica de faiscamento em dez aplicações por cinco minutos sobre as colônias, demonstrou que após 48 horas $90 \%$ das placas submetidas ao HF não tiveram crescimento de candida, já as placas que não receberam aplicação tiveram crescimento normal (11).

Vale ressaltar que estudos também indicam a aplicação de outros recursos associados, como o laser, para aumentar a efetividade dos resultados na reparação tecidual. Estudo experimental em ratos comparou a ação do laser GaAlInP e do gerador de alta frequência no tratamento de feridas cutâneas, com o objetivo de avaliar a ação associada dos dois recursos, bem como a ação individual de ambos. Os dois recursos proporcionaram melhorias comparadas ao grupo controle, no entanto, a associação dos dois foi a que apresentou melhor resultado (13).

Consideram-se limitações ao estudo o número reduzido da amostra em virtude dos critérios de exclusão utilizados e o período utilizado para a aplicação do gerador de alta frequência, com dez aplicações, um tempo curto quando comparado a outras pesquisas (10). Portanto, os resultados indicam uma tendência à melhor cicatrização e diminuição do tamanho da área com mais intervenções.

Nessa perspectiva, esta pesquisa agrega valor à procura de alternativas de tratamento para esses pacientes, deixando evidências de que mais estudos são necessários. Apesar de a ozonioterapia ser utilizada frequentemente na área da dermatofuncional, são escassos os estudos clínicos controlados para verificação da efetividade deste recurso. 


\section{Conclusão}

Os resultados obtidos sugerem que a aplicação da alta frequência em pacientes com úlceras por pressão proporciona melhora na cicatrização das úlceras, bem como a diminuição da área de superfície da lesão.

\section{Referências}

1. European Pressure Ulcer Advisory Panel, National Pressure Ulcer Advisory Panel. Treatment of pressure ulcers: quick reference guide. 2009 [acesso 1 nov 2013]. Disponível em: http://www.epuap.org/ guidelines/Final_Quick_Treatment.pdf

2. Rocha JA, Miranda MJ, Andrade MJ. Abordagens terapêuticas das úlceras de pressão: intervenções baseadas nas evidências. Acta Med Port. 2006;19:29-38.

3. Araújo TM, Araújo MFM, Caetano JA, Galvão MTG, Damsceno MMC. Diagnósticos de enfermagem para pacientes em risco de desenvolver úlcera por pressão. Rev Bras Enferm. 2011;64(4):671-6.

4. Mistiaen P, Ament A, Francke AL, Achterberg W, Halfens R, Huizinga J, et al. An economic appraisal of the Australian Medical Sheepskin for the prevention of sacral pressure ulcers from a nursing home perspective. BMC Health Serv Res. 2010;10(226):1-10.

5. Anders J, Heinemann A, Leffmann C, Leutenegger M, Pröfener F, von Rentein-Kruse W. Decubitus ulcers: pathophysiology and primary prevention. Dtsch Arztebl Int. 2010;107(21):371-82.

6. Bluestein D, Javaheri A. Pressure ulcers: prevention, evaluation, and management. Am Fam Physician. 2008;78(10):1186-94.

7. Assadian 0, Oswald JS, Leisten R, Hinz P, Daeschlein G, Kramer A. Management of leg and pressure ulcer in hospitalized patients: direct costs are lower than expected. GMS Krankenhhyg Interdiszip. 2011;6(1):1-7.

8. White-Chu EF, Reddy M. Wound care in short-term rehabilitation facilities and long-term care: special needs for a special population. Skinmed. 2012;10:75-81.

9. Balakatounis KC, Angoules AG. Low-intensity electrical stimulation in wound healing: review of the efficacy of externally applied currents resembling the current of injury. Eplasty. 2008;8:283-91.
10. Borges FS. Dermato-Funcional: modalidades terapêuticas nas disfunções estéticas. São Paulo: Phorte; 2006.

11. Higa DR, Cese PC, Falcão RMM, Cese AC, Chang MR, Borges FS, et al. Efeito do gerador de alta frequência sobre cultura de candida tropicalis. R Esp Fisiot. 2007;1(1):1-8.

12. Barros VCC, Santos VNS, Santos FB. Tratamento de verruga ungueal causada por HPV com uso do gerador de alta freqüência: relato de caso. R Esp Fisiot. 2007, 1(2):1-5.

13. Sá HP, Nunes HM, Santo LAE, Oliveira GC Junior, Silva JMN, Carvalho KC, et al. Estudo comparativo da ação do laser GaAlInP e do gerador de alta frequência no tratamento de feridas cutâneas em ratos: estudo experimental. ConScientiae saúde. 2010;9(3):360-6.

14. Valacchi G, Bocci V. Studies on the biological effects of ozone: 11. Release of factors from human endothelial cells. Mediators Inflamm. 2000;9:271-6.

15. Traina AA. Efeitos biológicos do ozônio diluído em água na reparação tecidual de feridas dérmicas em ratos [tese]. São Paulo: Universidade de São Paulo; 2008.

16. Kim HS, Noh SU, Han YW, Kim KM, Kang H, Kim HO, et al. Therapeutic effects of topical application of ozone on acute cutaneous wound healing. J Korean Med Sci. 2009;24(3):368-74.

17. Travagli V, Zanardi I, Valacchi G, Bocci V. Ozone and ozonated oils in skin diseases: a review. Mediators Inflamm. 2010;2010:1-9.

18. Bocci VA, Zanardi I, Travagli V. Ozone acting on human blood yields a hormetic dose-response relationship. J Transl Med. 2011;9(66):1-11.

19. Santos VLCG, Azevedo MAJ, Silva TS, Carvalho VMJ, Carvalho VF. Adaptação transcultural do pressure ulcer scale for healing (PUSH) para a língua portuguesa. Rev Latino-Am Enfermagem. 2005;13(3):305-13.

20. Bates-Jensen BM. Quality indicators for prevention and management of pressure ulcers in vulnerable elders. Ann Intern Med. 2001;135(8 pt 2):744-51.

21. Oien RF, Håkansson A, Hansen BU, Bjellerup M. Measuring the size of ulcers by planimetry: a useful method in the clinical setting. J Wound Care. 2002;11(5):165-8.

22. Miot HA, Mendaçolli TJ, Costa SV, Haddad GR, Abbade LPF. Úlceras crônicas dos membros inferiores: avaliação pela fotografia digital. Rev Assoc Med Bras. 2009;55(2):145-8. 
23. Rodrigues BAFA. Classificação automática de lesões cutâneas [dissertação]. Porto: Universidade do Porto, 2011.

24. Recio AC, Felter CE, Schneider AC, McDonald JW. High-voltage electrical stimulation for the management of stage III and IV pressure ulcers among adults with spinal cord injury: demonstration of its utility for recalcitrant wounds below the level of injury. J Spinal Cord Med. 2012;35(1):58-63.

Recebido: 27/06/2012

Received: 06/27/201

Aprovado: $31 / 07 / 2013$

Approved: 07/31/2013 